\title{
Reflective Classroom Practice for Effective Classroom Instruction
}

\author{
Nalliveettil George Mathew \\ English Department Assistant Professor, Aljouf University, Saudi Arabia \\ E-mail: ngeorgemathew09@gmail.com
}

\author{
Received: November 7, 2011 Accepted: November 21, 2011 Online Published: May 17, 2012 \\ doi:10.5539/ies.v5n3p205 \\ URL: http://dx.doi.org/10.5539/ies.v5n3p205
}

\begin{abstract}
Improving English language skills of learners is a strenuous task because of the variations in culture, background and learning styles. This strenuous task is further aggravated when English teachers realizes the proficiency level of students is far too low that his/her expectation. In most of the ESL and EFL context, English teachers rely on mid-term test to evaluate the proficiency level of the students. Blame game follows when there are too many failures in the classroom. Teachers blame the students for giving least importance to English language which resulted in low scores while the students blame the teacher for making the exam tough. The college/university management considers failure of students as a failure of the teachers in the classroom teaching.

The information presented in this paper is an alarming wakeup call and a reminder for the teachers to be constant self-evaluators of their classroom teaching rather than waiting for the results of a test to understand the students' progress in classroom. This paper gives insights to the struggling teachers to succeed through reflective teaching practices.
\end{abstract}

Keywords: Reflection, Practice, Classroom, Instruction, English teachers, Teaching, Learning

\section{English Language Education}

English language has become the medium of communication in many domains of public and private sector. To get on in these sectors it is essential to master English language skills. The government and private institutions have recognized the demand for the General English and proficiency courses. There has also been an increase in the percentage of teachers imparting English language in educational institutions. A quick look at English language instructors imparting English language education indicate that there are teachers who have the requisite educational qualification in the specific language English while others have some knowledge of English language. The recruitment and selection process of English teachers for a prospective job varies across the globe based on the requirements and the need of a particular educational institution. However, imparting English language education to the learners is a primary concern in English as a foreign language and second language classrooms.

Exploring the needs of the learners in a classroom is a tedious work and so most of the English teachers either have informal discussion with their students or ask them to write about what students expect from the course. In their enthusiasm, students make a list of skills they would like to improve in the semester. There are teachers who try to negotiate with the students and agree to focus on specific language skills required for all round improvement while the enthusiasm of other teachers vanishes when they find too many variations in the learners needs. Improving English language skills of learners is a strenuous task because of the variations in culture, background and learning styles. This strenuous task is further aggravated when English teachers realizes the proficiency level of students is far too low than his/her expectation. In most of the ESL and EFL context, English teachers rely on mid-term test to evaluate the proficiency level of the students. Blame game follows when there are too many failures in the classroom. Teachers blame the students for giving least importance to English language which resulted in low scores while the students blame the teacher for making the exam tough. The college/university management considers failure of students as a failure of the teachers in the classroom teaching. On the positive side, this information is an alarming wakeup call and a reminder for the teachers to be constant self-evaluators of their classroom teaching rather than waiting for the results of a test to understand the students' progress in classroom. English teachers also should realize it is not a formal test that could give the data of the students learning progress but a regular analysis of the classroom procedures and methods. Everyday classroom teaching-learning practices has to be considered as a rich kind of data for teachers to use as a basis for reflective practice on teaching and learning approaches. 


\section{Assessing the Success of Classroom Resources}

An important and common resource in the classroom is the textbook. Curriculum designers recommend a standard textbook which are either available in the printing press or a tailored version which has been written solely for the purpose of a target group. Instructional activities in these textbooks are designed to improve the communication skills of the students. In most of the English as foreign language and second language classrooms the objectives specified in the instructional activities of the prescribed textbook and the instructional outcomes may not match to the proficiency levels of the students. Failure to succeed in the specified instructional outcomes is either ignored or blamed to the high expectations of the course material. A reflective teacher practitioner systematically reflects the reasons for failure to succeed and incorporate necessary modifications while teaching similar instructional activities at a later stage of his/her career.

There are English teachers who over-rely on textbooks and ignore other aids or materials for the classroom. Using the textbooks as the sole source of information may hinder progress because it narrows down the students perspective only to a specific content presented. A reflective teacher has to assess and evaluate the relevance and significance of the content and add new content if the given content is old and outdated. Learning to use the textbook sparingly and supplementing materials relevant to learners needs make the teaching-learning environment lively and interesting. The three important attributes of a reflective teacher that Dewey (1933) identified are open-mindedness, responsibility and wholeheartedness. An open-minded teacher listens to more than one side of the issue and gives attention to alternative issues. A responsible teacher carefully considers different alternatives and takes the responsibility of the success or failure of classroom teaching to his or her stride. The attribute of whole-heartedness give scope for evaluating the classroom procedures through self-evaluation or evaluation by the peers and make meaningful changes for effective classroom instruction.

\section{Purposeful Teaching and Learning}

Teaching is purposeful interaction intended to promote learning as it involves teacher and learner engaging in joint purposeful activity. The effectiveness of this joint purposeful activity is often linked to the prescribed course book, the facilitator and teaching methodology. Teaching English as a second language is often received with mixed feelings by the learners. In a English as a second language classroom, there are learners who are overconfident of their knowledge in English while there are learners who are passionate to improve their proficiency in English language. English teachers also experience situations where students express their displeasure towards learning English. Teachers are confused and bewildered when students respond negatively to classroom teaching and testing patterns. Lesson plans with aims, objectives and possible outcomes are made mandatory by many educational institutions. A lesson plan may not always meet the expectations and not everything a teacher plans gets taught. In order to be effective, a teacher must be able to respond to students' errors, unexpected questions and learning opportunities that arise. These familiar and unfamiliar attitudes of the second language learners give interesting insights for classroom instruction.

Reflective practice refers to deliberate thinking about actions that has already taken place and deliberate examination of classroom procedures, attitudes and interactions. Zeichner and Liston (1996) says "If a teacher never questions the goals and the values that guide his or her work, the context in which he or she teaches, or never examines his or her assumptions, then it is our belief that this individual is not engaged in reflective teaching." Simply thinking about teaching, planning our lessons or thoughtfully marking papers does not necessarily constitute reflective teaching. This practice involves critical examination of self motivation and thinking. It is a move towards critical thinking to improve productivity in teaching and students' learning. Learning involves acquiring competence through action and experience while teaching involves engaging the learners in a process of activity that is likely to result in success of intended learning outcomes. Helping learners to understand the reasons for failures and creating awareness in self-correction can improve students' classroom performance. Awareness that learning is sometimes frustrating, the hardest, most demanding and ultimately most rewarding help the learners to be accountable and committed to their learning.

\section{Reflective Teaching: Teacher Talk Time and Student Talk Time}

Communicative language teaching is considered as a learner-centered methodology and most of the universities across the globe recommend this approach in English language classroom. Language learners are expected to be active in communicative language teaching classroom. Students are encouraged communicate in real life situations which indirectly reduces Teacher Talk Time. The need for oral lecture or instruction in a classroom can be directly controlled by the teacher through reflective practice. If an English language teacher has the habit of talking more to explain a concept in the classroom, students remain as passive listeners. Research on classroom teacher talk time and student talk time indicates that by limiting the teacher talk time to $20 \%$ to $30 \%$ of class time and remainder $70 \%$ 
to $80 \%$ can be devoted to speaking/use of the language by the students. The successful use of $70 \%$ to $80 \%$ of class time for imparting effective language learning to students seems to be a difficult task for the teachers. Through constant practice and self-evaluation of methods and materials used in the classroom instruction, Reflective English language practitioners learn to overcome the initial difficulty of using the student talk time by making appropriate amendments to their classroom teaching.

In a communicative language teaching classroom students are expected to participate and respond to the interactive sessions while teachers have to be active facilitators of their students' learning. The role of teacher is to observe and monitor the communicative activities of the students. The responsibility of the students is more as their participation in an activity makes the communicative exercises more successful. The communicative approach to language teaching may pose difficulty to the teachers when working with new or unfamiliar learners. A language teacher might plan the classroom session meticulously but the things may not go according to the plan or may find it difficult to cope up with classroom situation. A reflective language teacher takes this situation to his/her stride because these are key moments for learning. David Schon (1987) says that in a carefully planned classroom session the teacher has to constantly monitor the session as it progresses. An awareness of the classroom session that is in progress allows a teacher to make changes as the situation demands. After the completion of a classroom session, the post-action of reflecting, analysing and evaluating informs a teacher of the subsequent planning and preparation leading to a cycle of continuing improvement.

Reflective practice in the language teaching classroom gives scope for the teachers to understand the learners' needs and abilities. In a learner-centred approach, the teachers can effectively encourage learners to reflect, evaluate, analyse and improve their own learning. Pedagogical practices that involve planning and teaching facilitates rich and effective learning experiences for students. Reflective teaching practitioners make sense of their work with students, language teaching and language learning. A critical pedagogical reflection of classroom teacher talk time and student talk time can be threatening and difficult because it forces a teacher to be honest and recognise the areas need to be improved. Honest reflections and evaluations of their pedagogies by way of questioning what they do and rethinking what they would do give scope for self-improvement and innovative teaching practices.

\section{Low Achievers and the Reflective Teacher}

Research has shown that academic achievement seems to be higher in those students who participate actively in the class as compared to those who are passive in class. Due to many constraints in the teaching-learning process, the passive students or the low achievers do not get adequate attention. Teaching and learning tends to become as two disconnected activities when teachers do not take responsibility for student learning and achievement. Failure to understand the problems or difficulties of low achievers can lead to situations where these students give up education or develop inferiority complex. Low achievers and passive learners are burden to the society because these students grow to be trouble makers for their parents at home. It is the responsibility of the teacher to give adequate attention to individual students and more so to low achievers and passive students. It is a strenuous task for the teachers to deal with low achievers because these learners associate learning with negative feelings and dislike classroom environment. A reflective teacher on the other takes it as a learning experience to deal with low achievers and in the process devise ways to motive these students. Most of what teachers learn is learned on the job and reflective practice gives an opportunity for every teacher to improve his/her teaching for career growth.

Low achievement or poor progress in language studies is due to various factors, some of which are visible while most of it goes invisible. Student-teacher gap and school-parent gap are other factors related to low-achievers which go unnoticed. Many teachers expect students to adjust to the way they teach, rather than adjusting their teaching to the way students learn. Reflective practitioners identify these gaps and create conditions needed to raise the achievement levels of these students.

\section{Challenges and Constraints of a Reflective Teacher in Practice}

The challenge for each teacher at the classroom interface is to translate insights into effective practice and this requires conversation with self. Richard and Lockhart (1994) suggest teachers to collect data about their teaching, examine their attitudes, beliefs, assumptions and teaching practices. Self analysis can be the basis for critical reflection about teaching-learning process in the classroom. According to Karen and Robert (1993), problems arise out of a sense of discomfort or desire to a change. In some contexts, information from another source like an individual group or a report helps to sort out the problem. In most of the situations, it's one's own experience that helps an individual to identify problems.

Reflective teaching is complex because of the involvement of self, the students, the school and society at large. A reflective practitioner needs to have wide knowledge and possible solutions to an issue of concern. Reflective teaching is time consuming and time management is a constraint because there are other life issues which may 
demand urgency for a professional teacher. At the academic level also time is a constraint for reflection to teacher practitioners because of the increased workload in a shortened semester. Serafini (2002) says that it is futile or even naïve to suggest teachers to slow down, step back and spend more time thinking, reflecting and talking about their instructional practices and belief. According to Serafini, the four aspects of reflection are time, distance, dialogue and preferred vision. A teacher needs time to think over what has happened and what should happen in teaching-learning process. It requires cooperation from other individuals living at his work place for this time to be available. Distance refers to a critical perspective where the teacher evaluates his/her teaching using methods like audio/video recording in order to have a better understanding of his/her classroom teaching. A critical self-reflection of the teaching-learning process by self-questioning the classroom procedures can give insights for bringing about productive changes in the classroom management. Preferred vision that is consciously built towards achieving positive results in the classroom gives a direction for teachers to take an active role within their social and educational environment. According to Jonassen (1999), the intellectual process of reflection, analysis and interpretation undertaken by teachers to improve their teaching in many ways reflect the learning processes expected of students. A reflective teacher sees what he/she does from as many angles as possible and translates insights into active change and solves new problems through self evaluation.

\section{Reflective Practice for Professional Development}

The ever changing cultural and global contexts require knowledgeable, caring, responsive and responsible teachers. Developments in science and technology made classroom teaching-learning process more challenging. Most of the English course books are integrated with audio-visual elements. Integrating audio and audio-visual elements in the course curriculum triggered a mixed response from the teaching community. A study conducted by Mathew (2009) on the teaching-learning process of English language classrooms in the engineering colleges affiliated to Jawaharlal Nehru Technological University, India reveal the difficulties of teachers and students in the classroom. Students responded to a reflective questionnaire and opined that the prescribed course book is not suitable to improve communication skills in the English language. English teachers' response to a similar kind of questionnaire indicates that most of the English teachers have not attended the training programmes to update their methodology or skills in teaching English. An analysis of the prescribed course book 'Learning English: A communicative approach' reveals that all the chapters in the English course books have the same type of exercises throughout the course books - which consist of comprehension, vocabulary, Grammar, Listening, Speaking, Writing and language games. Findings of the study reveal that teachers are more concerned with the completion of syllabus and reflective teaching is rarely practiced. Lecturing and explanation are predominant methodologies for classroom instruction while the scope for interactive instruction is too narrow due too many constraints. The findings also suggest a wide gap in the teaching beliefs and actual classroom experiences. Failure to reflect on the real classroom experiences and habitually following the instructions given in a language exercise increases the likelihood of serving one's own ego rather than help students learn.

Upgrading classrooms with electronic gadgets either made the classroom successful or more miserable. Availability of power point presentations and tailored made resources in the electronic and print media gave solace to the practicing teachers. On the other hand, these resources remain as chunks of knowledge without reflective practice for techno-literate teachers. Teachers are sometimes confused and bewildered when these resources give a negative impact in the classroom. In the professional development of a practicing teacher, a blend of resources and reflective practice improves the quality of teaching. It is a pathetic situation when students rate the classroom teaching of highly qualified teachers as obsolete. A process of self-observation and self-evaluation of classroom instruction lead to improvements in the teaching-learning process. Building reflective practice on the skills that these teachers have already developed add significantly to their career growth. Challenges are part of moving on towards professional development. In a classroom, the diverse characteristics of the students may make it difficult to teach them how to be reflective learners. Since each student as an individual has unique learning styles with multiple intelligences, needs, interests and backgrounds, it is difficult to teach them how to be reflective learners. A teacher in practice has to constantly update skills and knowledge for effective classroom instruction.Pollard and Tann (1989) regard reflective teaching as cyclic process by which the teacher interprets his/her classroom practice. Visualizing and placing oneself at every step of figure 1 make the reflective practice more meaningful and effective for classroom teaching-learning process.

Insert Figure 1 here.

Figure 1 suggests that a teacher has to continuously evaluate his/her own behavior and experiences so that students maximize their learning. Involvement of self and students in a process of self observation/self evaluation give insights about beliefs, assumptions and values attached to practices and experiences. Richards (1990) points out that experience coupled with reflection is a powerful impetus for teacher development while teaching experience alone is 
insufficient. Reflective teaching informs a teacher that he/she is a facilitator of teaching-learning and has a major contribution to make towards its success. Bailey (1997) says that reflective teaching is about a skilled teaching of knowing what to do. A skilled teacher examines his/her work, collects information from the classroom, analyses and evaluates this information to make changes and improvements in the teaching. This multi-dimensional approach of self inquiry may turn a teacher to be a researcher as these personal experiences are shared in national and international teaching forums. It is a means to solve problems in a systematic manner during the professional journey of teaching.

\section{Conclusion}

The reflective practices discussed in this paper involve an openness that requires teachers to challenge their own assumptions and continue to improve skills needed for effective classroom instruction. There are teachers who might occasionally provide stimulating session and exhibit confidence and an ability to inspire or motivate groups of learners. There are teachers who experience depths of despair when a classroom session does not work in their favor or when students give negative feedback about their sessions. There are teachers who struggle to plan classes, explain properly, to assess and are deficient in whole range of necessary skills required for classroom management. All the critical incidents that a teacher trainer, a beginner in the teaching profession and an expert teacher experience in the classroom should be considered as occasions and opportunities for learning. Reflecting critical incidents can lead to solutions that can be transferable to other learning situations. Success in teaching is not just a matter of luck but results from thorough planning, preparation and knowing the learners through reflection, evaluation and practice.

\section{References}

Acheson, K., \& M. Gall. (2003). Clinical supervision and teacher development: preservice and inservice applications. Danvers, MA: John Wiley \& Sons, Inc.

Adger, C., C. Snow \& D. Christian (2003). What teachers need to know about language. McHenry, IL: Delta Systems \& Washington, DC: Centre for Applied Linguistics.

Allen, L. Q. (2000). Culture and the ethnographic interview in foreign language teacher development. Foreign Language Annals 33.2, 51-57. http://dx.doi.org/10.1111/j.1944-9720.2000.tb00889.x

Allwright, D. (2003). A brief guide to exploratory practice. Language Teaching Research, 72, 109-112. http://dx.doi.org/10.1191/13621688031r117oa

Allwright, D. (2005). From teaching points to learning opportunities and beyond. TESOL Quarterly, 39(1), 9-31.

Allwright, D., \& K. M. Bailey (1991). Focus on the language classroom: an introduction to classroom research for language teachers. New York: Cambridge University Press.

Allwright, D., \& R. Lenzuen (1997). Exploratory practice: work at theCultura Inglesa, Rio de Janeiro, Brazil. Language Teaching Research, 1(1), 73-79. http://dx.doi.org/10.1177/136216889700100105

Appel, J. (1995). Diary of a language teacher. Oxford: Heinemann.

Arkoudis, S. (2003). Teaching English as a second language in science classes: incommensurate epistemologies. Language and Education, 17(3), 161-173. http://dx.doi.org/10.1080/09500780308666846

Atay, D. (2004). Collaborative dialogue with student teachers as a follow-up to teacher in-service education and training.Language Teaching Research, 82, 143-162. http://dx.doi.org/10.1191/1362168804lr138oa

Bailey, F., M. Hawkins, S. Irujo, D. Larsen-Freeman, E. Rintell \& J. Willett (1998). Language teacher educators' collaborative conversations. TESOLQuarterly, 32, 536-546. http://dx.doi.org/10.2307/3588124

Bailey, K. (1997). Reflective teaching: situating our stories. Asian Journal of English Language Teaching, 7, 1-19.

Bailey, K.M. (1990). The use of diary studies in teacher education programmes. In J.C. Richards and D. Nunan (Eds), Second Language Teacher Education (pp. 215-226). New York: Cambridge University Press

Bartels, N. (2002). Professional preparation and action research: only for language teachers? TESOL Quarterly, 36(1), 71-79. http://dx.doi.org/10.2307/3588361

Bartels, N. (ed.) (2005). Applied linguistics and language teacher education. New York: Springer.

Bartlett, Leo. (1990). Teacher development through reflective teaching. In J.C. Richards and D. Nunan (Eds), Second Language Teacher Education (pp. 2002-214). New York: Cambridge University Press

Basile, C., \& F. Olson (2003). Problem-based learning: reflective coaching for teacher educators. Reflective Practice 4(3), 291-302. http://dx.doi.org/10.1080/1462394032000112200 
Bolitho, R. (2003). Training and applied linguistics. The Language Teacher, 23, 4-7.

Bolton, G. (2002). Reflective practice, writing and professional development. London: Paul Chapman.

Boon, A. (2003). On the road to teacher development: awareness, discovery and action. The Language Teacher, 27, 3-7.

Boon, A. (2005). Is there anybody out there? Essential Teacher, 2(2), 38-41.

Borg, S. (2003a). Teachers' involvement in TESOL Research. TESOL Matters, 13(3), 1-5.

Borg, S. (2003b). Teacher cognition in language teaching: a review of research on what language teachers think, know, believe, and do. Language Teaching, 36(2), 81-109. http://dx.doi.org/10.1017/S0261444803001903

Breen, M. P., \& A. Littlejohn (eds.) (2000). A process syllabus in a methodology course: experiences, beliefs, challenges. Cambridge: Cambridge University Press.

Brockett, R. G., \& R. Hiemstra (1991). Self-direction in adult learning: perspectives on theory, research, and practice. NewYork: Routledge.

Brumfit, C. (ed.) (1983). Language teaching projects for the Third World (ELT Documents 116). London: Pergamon Press \& British Council.

Burns, A. (2005). Action research: an evolving paradigm? Language Teaching, 38(2), 57-74. http://dx.doi.org/10.1017/S0261444805002661

Buzzelli, C., \& B. Johnston (2002). The moral dimensions of teaching: language, power, and culture in classroom interaction. New York: Routledge.

Creese, A. (2005). Teacher collaboration and talk in multilingual classrooms. Clevedon: Multilingual Matters.

Damron, J. (2005). Encouraging professional development among pre-service teachers. The Teacher Trainer Journal 19.1, 4-8.

Dewey, J. (1933). How we think. Madison: University of Wisconsin Press.

Elder, C. (2001). Assessing the language proficiency of teachers: are there any border controls? Language Testing, $18(2), 149-70$.

Freeman, D. (1982). Observing teachers: three approaches to in-service training and development. TESOL Quarterly, 16(1), 21-28. http://dx.doi.org/10.2307/3586560

Griffiths, M., \& S. Tann (1992). Using reflective practice to link personal and public theories. Journal of Education for Teaching, 18(1), 69-84. http://dx.doi.org/10.1080/0260747920180107

Guskey, T. R. (2002). Professional development and teacher change. Teachers and Teaching: Theory and Practice, 8(3), 381- 391.

Hansen, D. T. (2001). Exploring the moral heart of teaching: towards a teacher's creed. New York: Teachers College.

Harrington, H. (1994). Teaching and knowing. Journal of Teacher Education, 45, 190-198. http://dx.doi.org/10.1177/0022487194045003005

James, P. (2001). Teachers in action: tasks for in-service language teacher education and development. Cambridge: Cambridge University Press.

Johnson, K. E. (1992). Learning to teach: instructional actions and decisions of pre-service ESL teachers. TESOL Quarterly, 26(3), 507-535. http://dx.doi.org/10.2307/3587176

Jonassen, D. (1999). Designing constructivist learning environments. In C. M. Reigeluth (Ed.), Instructional-design theories and models, Volume II: A new paradigm of instructional theory, (pp. 215-239). Mahwah, NJ: Lawrence Erlbaum.

Mathew, N. G. (2009). A Study of the English Language Reading Strategies of Engineering Students in colleges affiliated to JNTU, Andhra Pradesh. Unpublished PhD dissertation. India: University of Hyderabad.

Pollard, A \& Tann, Sarah. (1989). Reflective teaching in the primary school. United Kingdom: Taylor \& Francis.

Ramani, E. (1987). Theorizing from the classroom. ELT Journal, 41(1), 3-11.

Raths, J., \& F. Lyman (2003). Summative evaluation of student teachers: an enduring problem. Journal of Teacher Education, 54(3), 206-216. http://dx.doi.org/10.1177/0022487103054003003 
Richards, J. (1998). Beyond training. Cambridge: Cambridge University Press.

Richards, J. (2004). Towards reflective teaching. The Language Teacher, 33, 2-5.

Richards, J. C., \& Lockhard, C. (1994). Reflective Teaching. New York: Cambridge University Press.

Richards, J., \& C. Lockhart (1994). Reflective teaching in secondlanguage classrooms. Cambridge: Cambridge University Press. http://dx.doi.org/10.1017/CBO9780511667169

Richards, J., \& T. Farrell (2005). Professional development forlanguage teachers: strategies for teacher learning. Cambridge: Cambridge University Press. http://dx.doi.org/10.1017/CBO9780511667237

Richards, Jack C. (1990). The teacher as self-observer. In Jack C. Richards, The Language Teaching Matrix. New York: Cambridge University Press. http://dx.doi.org/10.1017/CBO9780511667152.009

Robert, B. K., \& K. F. Osterman (1993). Reflective Practice for Educators. United States of America: Corwin Press Inc.

Schön, D. A. (1987). Educating the Reflective Practitioner. San Francisco: Jossey-Bass

Serafini, F. (2002). Reflective practice and learning, Primary Voices K-6. Urbana: Vol. 10, Iss. 4; 2.

Shin, J. (2003). The reflective L2 writing teacher. ELT Journal, 57(1), 3-10.

Sotto, E. (2001). When teaching becomes learning. London: Continuum.

Tsui, A. B. M. (2003). Understanding expertise in teaching. Cambridge: Cambridge University Press.

Van Lier, L. (1991). Inside the classroom: learning processes and teaching procedures. Applied Language Learning, 2(1), 29-69.

Wada, M., \& S. Brumby (1994). Team teaching. London: Longman. Woods, D. (1996). Teacher cognition in language teaching. Cambridge: Cambridge University Press.

Zeichner, K. M., \& Daniel P. Liston. (1996). Reflective teaching: An introduction. New Jersey: Lawrence Erlbaum Associates, Inc.

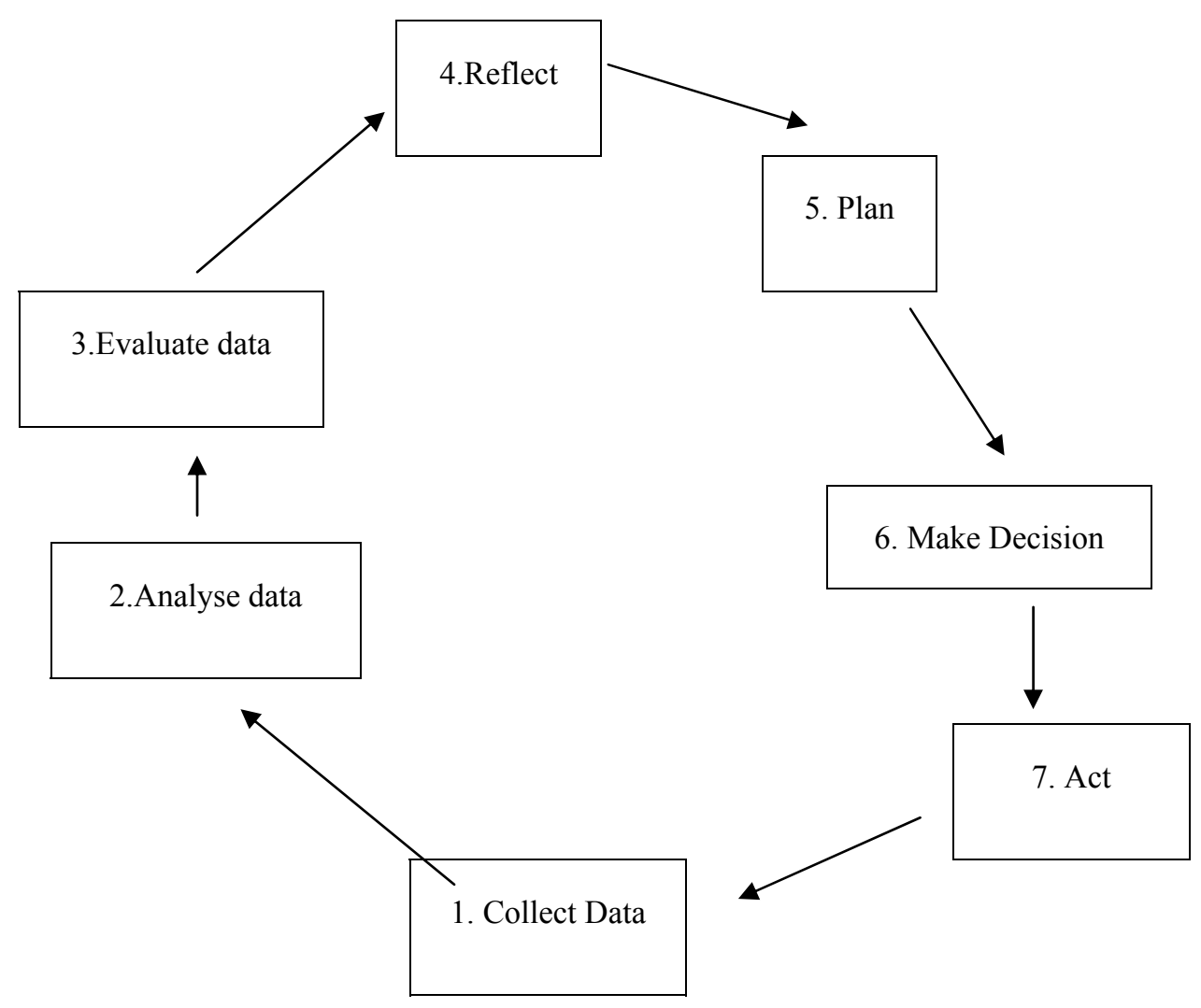

Figure 1. Cyclic flow of reflective teaching 